\title{
A Case Study On Learners' Perspectives On Technology For Learning
}

\author{
Christine Davies \\ University of Glamorgan
}

\section{Introduction}

In 2008, the University of Glamorgan embarked on a large-scale student expectations' project which subsequently featured in a SLiDA (Supporting Effective Learners in a Digital Age) case study (JISC, 2010). The project involved a survey of over 2,000 learners on many aspects of university life including the use of technology in learning, teaching and assessment, and gave rise to several important changes within the organisation. For example, online submission of assessments was introduced across the university, and training for both staff and students was put in place to ensure that the institutional virtual learning environment (VLE), in this case Blackboard, has widespread and consistent use. Another outcome of the project as a whole was the establishment of Student Voice Representatives (SVRs) who, amongst their many other roles, have a key input into policies on technology usage, for example by attending meetings of the Technology-Enhanced Learning Steering Group. In 2011, the technology-related aspects of this major survey were re-visited on a much smaller scale, giving rise to a case study which, though limited in size, had outcomes which are of value in the wider context of the use of technology for learning, teaching and assessment throughout higher education (HE).

\section{Methodology}

The institution's annual online Student Experience Questionnaire (SEQ) was used for this study. In consultation with student services representatives and SVRs, six non-mandatory questions on technology for learning were added to the questionnaire, and these are listed below. The first two questions ( $a$ and $b$ ) aimed to find out the extent of internet-enabled mobile phone usage. The following two questions (c and d) examined the range of technologies students had encountered and the influence of lecturers in that experience, with question e specifically looking at methods of communication. Lastly, question $f$ asked about overall satisfaction, and gave scope for students to comment further (comments could be added for all questions except question a). The questionnaire was produced using SurveyPirate (www.surveypirate. com) and was made available to students during a two-week period in May/June 2011.
a. Do you own an internet-enabled mobile phone or similar device (e.g. iPhone, Blackberry)?
b. If you own an internet-enabled phone, do you make use of it for learning in any way?
c. Which of the following has helped your learning in some way? (tick all that apply)
d. What technologies have you been directed to use by your lecturers? (tick all that apply) 
e. How have you communicated with your lecturers and other university staff over this adademic year? (tick all that apply)

f. Was the technology provided/available to you at the university as good as you expected?

\section{Observations}

A total of 133 students participated in the 2011 Student Experience Questionnaire, a significantly lower response rate than in previous years possibly due to the limited amount of time given to promoting the survey. Of these respondents, $82 \%$ were undergraduates and $18 \%$ postgraduates, with the majority (91\%) studying full time. 55 students answered the technology-related questions, i.e. $41 \%$ of total respondents. Their responses indicate the following:

Nearly $80 \%$ indicated that the technology provided by the university came up to their expectations. However, respondents also frequently noted deficiencies in the availability and capability of campus PC provision

$60 \%$ had an internet-enabled phone, but only half of these stated that it was used for learning

Nearly $80 \%$ stated that their own laptops were very useful to them, though only $33 \%$ valued wifi hotspots

Almost all lecturers used e-mail as a mode of communication, with other forms of online communication accounting for less than $2 \%$ of responses. Text-messaging was used by approximately $5 \%$.

Almost all lecturers directed their students to use the institutional VLE, yet the use of tools associated with the VLE, such as wikis and forums, was infrequent. Lecturers promoted online submission of assignments and online journals, but rarely appeared to suggest other tools or technologies.

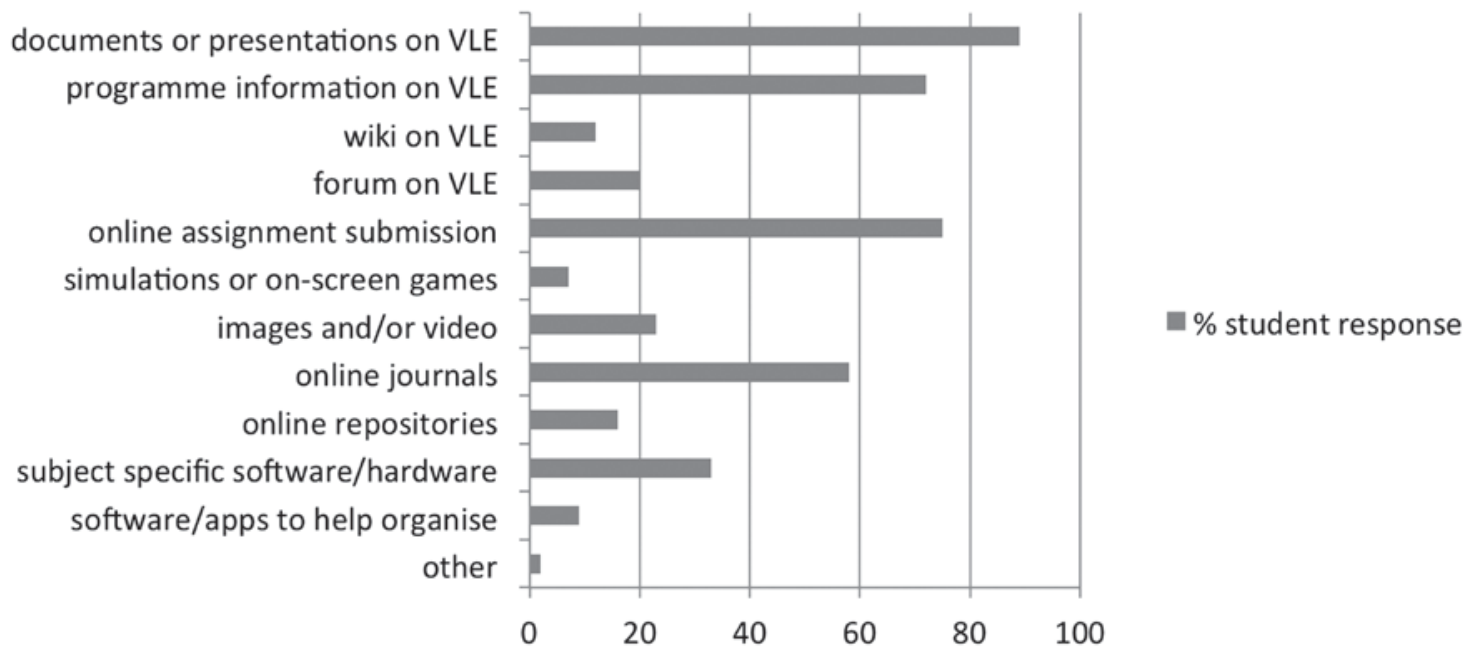

Figure 1 Bar-chart showing technologies to which students were directed to their lecturers 


\section{Inferences and Issues}

Though this study involved a small student sample, the data produced raise several issues that need to be explored further. Firstly, the limited response to the technology-focussed questions seems to indicate that learners are not automatic 'digital natives' when it comes to learning and, as indicated by the findings of the JISC Learner Experience studies (JISC, 2009), they are probably highly dependent on their tutors for guidance on any use of technology relating to their studies. Also, whilst mobile phones are frequently accepted as ubiquitous amongst the student population, it cannot yet be assumed that all learners can access online materials or modes of communication via mobile devices. The current case study indicates that smartphone ownership at the University of Glamorgan in May 2011 was around $60 \%$, yet at ALT-C 2011 it was reported that the equivalent value for London Metropolitan University students was $87 \%$ (Bradley, 2011). However, the NUS/HSBC Student Experience Survey for 2010-11 found that out of over 3,000 students, only $32 \%$ owned smartphones. Differences in survey methodology may play a part in these differences, and the rapid increase smartphone usage over the past year or so is also significant. Some variation is also likely to be attributable to institutional region and student intake.

The results also highlight ambiguities in the responses that may reflect weaknesses in the survey methodology. For example, most of the students answering the technology-related questions indicated that technology at the university was 'as good as expected', yet many made comments criticising the provision: does this mean that their expectations were low, but their satisfaction high? And do students tend to think of mobile phones and 'learning' as mutually exclusive? This problem of definition/interpretation is significant, and extends into the problem of experience, for it is difficult for learners to make meaningful comments about technologies they have never encountered. Even apparently simple observations may not have a straightforward basis: for example, it is not immediately obvious why wifi hot-spots were not highly value, and this is a clear case where student follow-up is required.

\section{Conclusions}

The above reflections highlight the importance of asking appropriate questions in appropriate ways in order to obtain accurate, inclusive data about students' experiences and perceptions of technology. As suggested by Desimone and Le Floch (2004), cognitive interview strategies may aid the process of question and survey design, and involvement of students throughout should have a highly positive impact. As a result of this study, future research in this area at the University of Glamorgan will involve SVRs and other student focus groups more closely both before and after survey activity to ensure more precise questions and better interpretation of responses. Additionally, more will be done to ensure that students are better informed about technology in the context of their learning.

\section{References}

Bradley, C. 2011. Our Students all have Mobile Phones: What do They Have and How are They Using Them for Learning?[Online]. Abstract 0187, ALT-C 2011 Abstracts, ALT Open Access Repository. Available at: http://repository.alt.ac.uk/id/eprint/2160 [Accessed 12 January 2012].

Desimone, L.M., and Le Floch, K.C. (2004) Are We Asking the Right Questions? Using Cognitive Interviews to Improve Surveys in Education Research. Education Evaluation and Policy Analysis, 26 (1), pp. 1-22.

JISC. 2009. Responding to Learners. [Online]. Available at: www.jisc.ac.uk/publications/ programmerelated/2009/respondingtolearners.aspx (Accessed 23 April 2011).

JISC. 2010. Supporting Effective Learners in a Digital Age (SLiDA). Case Studies: University of Glamorgan. [Online]. Available at: https://wiki.brookes.ac.uk/display/slidacases/Glamorgan [Accessed 28 April 2011]. 
Compass: The Journal of Learning and Teaching at the University of Greenwich, Issue 5, 2012

NUS/HSBC. 2010. Student Experience Full Report 2010/11. [Online]. Available at:

www.nus.org.uk/ PageFiles/12238/NUS-HSBC-Experience-report-web.pdf [Accessed

21 January 2012]. 